\title{
Thermochemical cycle based on solid intermediates for hydrogen storage and on-demand production
}

\author{
Anna Chiara Tizzoni ${ }^{1 *}$, Emiliana Mansi ${ }^{1}$, Salvatore $\mathrm{Sau}^{1}$, Annarita Spadoni ${ }^{1}$, Natale Corsaro ${ }^{1}$, Michela Lanchi $^{1}$, \\ Gianremo Giorgi ${ }^{1}$, Luca Turchetti $^{1}$ and Tiziano Delise ${ }^{1}$ \\ ${ }^{1}$ ENEA - Italian National Agency for New Technologies, Energy and Sustainable Economic Development, Via Anguillarese, 301, \\ 00123 Rome, Italy
}

\begin{abstract}
Thermochemical water splitting processes based on Sulfur-Iodine cycle can be conveniently improved using solid intermediates, in order to increase the global yield and avoid the use of concentrated acid at high temperatures. In this context, an innovative process has been conceived, where a metal oxide, namely $\mathrm{NiO}$, is reduced into oxygen and the correspondent metal, which can be suitably stored and reacted with steam into hydrogen when and where necessary. Data previously obtained and published, together with the integration of experimental results have been used to evaluate the technical feasibility and the heat duties of each step of the proposed cycle. The starting point was a Nickel compounds based process already extensively characterized, which has been modified using low toxic Iron (III) species as intermediates for oxygen formation. Based on the theoretical and experimental analysis carried out, the resulting cycle thermal efficiency is quite promising, about $19 \%$, also taking into account the hydrogen generation step.
\end{abstract}

\section{Introduction}

Solar driven thermochemical water splitting cycles (TWSC) are considered a valid alternative to the direct thermal water splitting, which can only occur at about $3500^{\circ} \mathrm{C}$, in very severe operating conditions which lead to serious issues related to materials and products separations [1]. Moreover, solar receivers present a limited thermal efficiency above $1000^{\circ} \mathrm{C}$ [2]. For these reasons, several TWSC processes were proposed in the last years, and, among them, the so called "Sulfur-Iodine" cycle [3][4][5] can be operated at relatively limited temperatures $\left(<900^{\circ} \mathrm{C}\right)$. In this cycle the water molecule is "incorporated" into sulfuric and hydriodic acids by the "Bunsen reaction". Then, both are thermally decomposed, the former at around $900^{\circ} \mathrm{C}$ into oxygen and sulfur dioxide, and the latter at about $500^{\circ} \mathrm{C}$, leading to hydrogen and iodine. Iodine and sulfur dioxide are recirculated to the Bunsen section, to be converted again into the two acid solutions. The cycle is schematized in Figure 1.

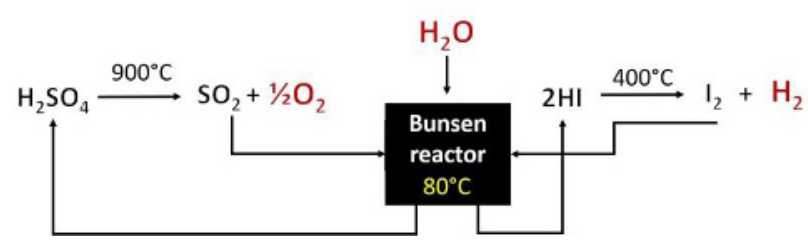

Fig. 1. Scheme of the "Sulfur Iodine" cycle

Compared to other TWSC, this process presents the advantage to employ commonly chemicals as intermediates, but also the drawback of a relative great number of reactive and separative phases, quite corrosive compounds at high temperatures, and the requirement of specific heterogeneous catalysts, with an important thermodynamic limitation for hydriodic acid cracking [4].
In this regard, the use of solid intermediates was investigated as an alternative solution to overcome some of the described issues, and Nickel compounds were proposed at this aim by Prosini et al [6]. The modified cycle is illustrated in Figure 2. Hydrogen is quantitatively produced at high purity and low temperature by reacting metallic Nickel with sulfuric acid, and a sulfate and an iodide are decomposed in place of the related acids. However, it is necessary to reduce the toxicity of the employed intermediates and it is important to consider a proper method to store and transport the hydrogen produced.

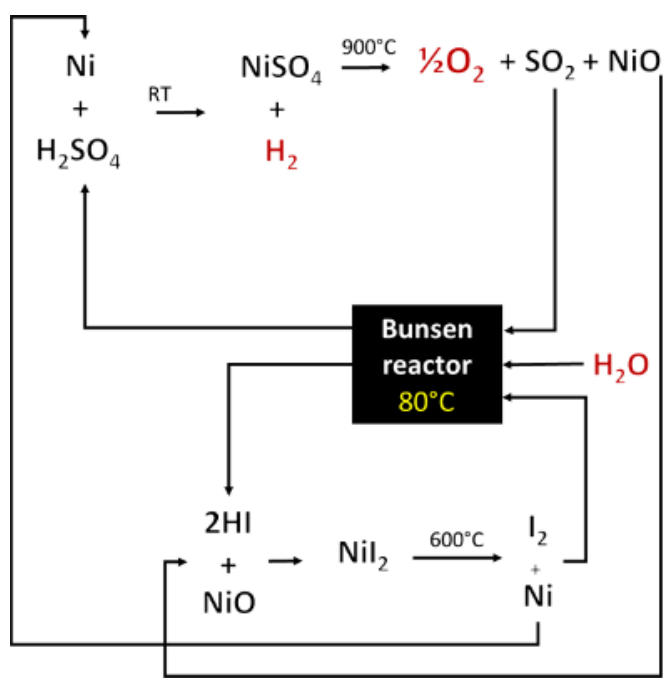

Fig. 2. Scheme of the "Sulfur-Iodine" cycle modified by using Nickel based intermediates [6]

ENEA, in the contest of the "Electric System Research Program", funded by the Italian Ministry of Ecological Transition (Implementation plan 2019-2021), has been continuing to investigate modified "Sulphur-Iodine" schemes, and, as a first result, as presented in the present

\footnotetext{
* Corresponding author: annachiara.tizzoni@enea.it
} 
paper, an innovative one has been conceived to limit the use of Nickel only to the HI section. This metal, being stable and dense, can be easily transported and used as reactant to obtain hydrogen "on-demand" when and where necessary, just reacting it with water. Available literature data were employed to demonstrate the feasibility of the process, integrated with a necessary experimental evaluation, that is, the study of the reaction yield between Iron (III) oxide and Sulfuric acid $50 \mathrm{wt} \%$.

\section{Materials and methods}

Analytical grade Iron (III) oxide $\left(\mathrm{Fe}_{2} \mathrm{O}_{3}\right)$ was purchased by Sigma-Aldrich, Sulfuric acid 96 wt\% (Carlo Erba) was used to prepare the $50 \mathrm{wt} \%$ solution.

The production yield of Iron (III) sulfate $\left(\mathrm{Fe}_{2}\left(\mathrm{SO}_{4}\right)_{3}\right)$ was determined by using a Mettler-Toledo thermogravimetric system, TGA/DSC1, with $70 \mu 1$ alumina crucible and chromatographic air as carrier gas $(40 \mathrm{Nml} / \mathrm{min})$.

\section{Results and discussion}

As discussed in the previous paragraph, it is necessary to reduce, at least partly, the toxicity of the employed intermediates and it is important to consider a proper method to store and transport the hydrogen produced. Regarding the former, only Nickel iodide decomposition has to date been investigated [7], but it is still possible to utilize a different and safer sulfate, namely the Ferric salt $\left(\mathrm{Fe}_{2}\left(\mathrm{SO}_{4}\right)_{3}\right)$. Moreover, the cycle can be modified in order to obtain the cracking of Nickel oxide $(\mathrm{NiO})$, producing Nickel to be employed as hydrogen store source on demand. This way, the resulting metal can be easily accumulated and transported, aso considering its high density and stability, thus providing a suitable method for hydrogen storage.

The involved reactions, balanced to achieve one mole of Nickel and half mole of Oxygen, are summarized in Table 1. The core of the process is the Bunsen reaction (Eq. I), where aqueous solutions of Sulfuric acid $\left(\mathrm{H}_{2} \mathrm{SO}_{4}\right)$ and Hydriodic acid (HI) are produced, at a concentration of about, respectively, $50 \mathrm{wt} \%$ and $57 \mathrm{wt} \%$. In order to separate the two phases, an excess of iodine must be introduced, with a ratio of around 3.5:1 (mol $\mathrm{I}_{2} / \mathrm{mol}$ HI)[8][9]. The two acids are purified according to the scientific literature[10] and reacted following equations III and VI.

Table 1. Reactions, steps and heat duties for the proposed thermochemical cycle

\begin{tabular}{|c|c|c|c|c|}
\hline & Step & $\mathrm{T}\left({ }^{\circ} \mathrm{C}\right)$ & $\begin{array}{c}\text { Heat duty } \\
(\mathrm{k} D\end{array}$ & Ref. \\
\hline I & 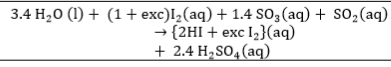 & $80 \div 120$ & Exothermic & [5] \\
\hline II & $2.4 \mathrm{H}_{2} \mathrm{SO}_{4}\left(50 \mathrm{wt} \%\right.$ )heating from 100 to $170^{\circ} \mathrm{C}$ & $100 \rightarrow 170$ & 11 & [11] \\
\hline III & $\begin{aligned} 0.8 \mathrm{Fe}_{2} \mathrm{O}_{3}(\mathrm{~s})+2.4 \mathrm{H}_{2} \mathrm{SO}_{4}(\mathrm{aq}) & \\
& \rightarrow 0.8 \mathrm{Fe}_{2}\left(\mathrm{SO}_{4}\right)_{3}(\mathrm{~s})+2.4 \mathrm{H}_{2} \mathrm{O}(\mathrm{g})\end{aligned}$ & 170 & 185 & {$[12][13]$} \\
\hline IV & $0.8 \mathrm{Fe}_{2}\left(\mathrm{SO}_{4}\right)_{3}(\mathrm{~s})$ heating from 120 to $675^{\circ} \mathrm{C}$ & $170 \rightarrow 675$ & 173 & [14] \\
\hline $\mathrm{v}$ & $\begin{array}{c}0.8 \mathrm{Fe}_{2}\left(\mathrm{SO}_{4}\right)_{3}(\mathrm{~s}) \rightarrow \\
\rightarrow 0.8 \mathrm{Fe}_{2} \mathrm{O}_{3}(\mathrm{~s})+\mathrm{SO}_{2}(\mathrm{~g})+1.4 \mathrm{SO}_{3}(\mathrm{~g}) \\
+0.5 \mathrm{O}_{2}(\mathrm{~g})\end{array}$ & 675 & 412 & [12] \\
\hline vI & 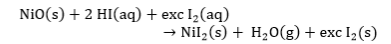 & 100 & -63 & [6] [13][15] \\
\hline VII & $\mathrm{NiI}_{2}(\mathrm{~s})$ Iodine removal by evaporation & $100 \rightarrow 180$ & 235 & [15] \\
\hline VIII & $\mathrm{NiI}_{2}(\mathrm{~s})$ heating from 100 to $600^{\circ} \mathrm{C}$ & $100 \rightarrow 600$ & 42 & [16] \\
\hline IX & $\mathrm{Ni}_{2}(\mathrm{~s}) \rightarrow \mathrm{Ni}(\mathrm{s})+\mathrm{I}_{2}(\mathrm{~g})$ & 600 & 141 & [6] \\
\hline$\underset{\mathbf{I} \div \mathbf{I X}}{\operatorname{Sum}}$ & $\mathrm{NiO}(\mathrm{s}) \rightarrow \mathrm{Ni}(\mathrm{s})+0.5 \mathrm{O}_{2}(\mathrm{~g})$ & & 1199 & \\
\hline $\mathrm{x}$ & On demand: $\mathrm{Ni}(\mathrm{s})+\mathrm{H}_{2} \mathrm{O}(\mathrm{g}) \rightarrow \mathrm{NiO}(\mathrm{s})+\mathrm{H}_{2}(\mathrm{~g})$ & 200 & 63 & $\begin{array}{c}{[13][15]} \\
{[16][17][18]}\end{array}$ \\
\hline$\underset{I \div \mathbf{X}}{\text { Sum }}$ & $\mathrm{H}_{2} \mathrm{O} \rightarrow \mathrm{H}_{2}+\frac{1}{2} \mathrm{O}_{2}$ & & 1262 & \\
\hline
\end{tabular}

In reaction III, Ferric oxide $\left(\mathrm{Fe}_{2} \mathrm{O}_{3}\right)$ reacts with the aqueous sulphuric acid solution producing the corresponding sulfate, which, in turn, is heated up to $675^{\circ} \mathrm{C}$ (step IV). The heat duty reported for reaction II includes also the enthalpy necessary to evaporate the formed water. $\mathrm{Fe}_{2}\left(\mathrm{SO}_{4}\right)_{3}$ is then decomposed under air atmosphere into sulphur dioxide $\left(\mathrm{SO}_{2}\right)$, sulphur tri-oxide $\left(\mathrm{SO}_{3}\right)$ and oxygen (reaction $\left.\mathrm{V}\right)$. At that temperature, the molar ratio between the produced $\mathrm{SO}_{2}$ and $\mathrm{SO}_{3}$ is about $0.42 / 0.58[12]$. It is important to note that the reaction III can occur with $\mathrm{H}_{2} \mathrm{SO}_{4}$ at $50 \mathrm{wt} \%[12]$, so avoiding an energetic costly sulfuric acid concentration. While the formation of the Iron(III) sulfate phase was demonstrated[12], no data were available about the actual reaction temperature and to confirm a quantitative neutralization between Iron(III) oxide and $\mathrm{H}_{2} \mathrm{SO}_{4}$ under those conditions. For this reason, a specific experimental verification was carried out for this work. Figure 3 shows the formation of Iron (III) sulfate, starting from $\mathrm{Fe}_{2} \mathrm{O}_{3}$ and using $\mathrm{H}_{2} \mathrm{SO}_{4} 50 \% \mathrm{wt}$, carried out in a TGA equipment using three different temperature ramps.

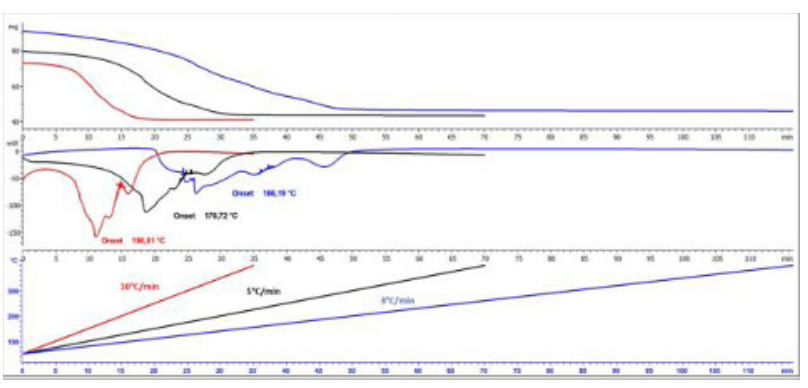

Fig. 3. TGA analysis of Iron (III) Sulfate formation, starting from $\mathrm{Fe}_{2} \mathrm{O}_{3}$ and using stoichiometric $\mathrm{H}_{2} \mathrm{SO}_{4} 50 \%$ wt; from top to bottom are shown: gravimetric curves, calorimetric curves and temperature ramps used $\left(3^{\circ} \mathrm{C} / \mathrm{min}, 5^{\circ} \mathrm{C} / \mathrm{min}\right.$ and $10^{\circ} \mathrm{C} / \mathrm{min}, \mathrm{N}_{2}$ carrier gas $40 \mathrm{Nml} / \mathrm{min}$ )

Two processes occur simultaneously: the concentration of sulfuric acid with $\mathrm{H} 2 \mathrm{O}$ loss and the reaction with oxide to give sulfate (with further water release). Table 2 reports the yields and reaction times for the three ramps considered. The formation rates were calculated considering the mass and molar balances below: 


$$
\begin{aligned}
& \text { mol } \mathrm{Fe}_{2} \mathrm{O}_{3} \text { initial }=\frac{\text { weight } \mathrm{Fe}_{2} \mathrm{O}_{3}}{\mathrm{MW} \mathrm{Fe}_{2} \mathrm{O}_{3}}+\frac{\text { weight } \mathrm{Fe}_{2}\left(\mathrm{SO}_{4}\right)_{3}}{\mathrm{MW} \mathrm{Fe}_{2}\left(\mathrm{SO}_{4}\right)_{3}} \\
& \text { weight final from } \mathrm{TGA}=\text { weight } \mathrm{Fe}_{2} \mathrm{O}_{3}+\text { weight } \mathrm{Fe}_{2}\left(\mathrm{SO}_{4}\right)_{3} \\
& \text { yield of } \mathrm{Fe}_{2}\left(\mathrm{SO}_{4}\right)_{3} \text { formation }=\frac{\text { weight } \mathrm{Fe}_{2}\left(\mathrm{SO}_{4}\right)_{3}}{\text { weight final from TGA }}
\end{aligned}
$$

Table 2. Reaction yields and times for: $\mathrm{Fe}_{2} \mathrm{O}_{3}+3 \mathrm{H}_{2} \mathrm{SO}_{4} 50 \%$ wt

\begin{tabular}{|c|c|c|c|}
\hline $\begin{array}{c}\text { Temperature } \\
\text { ramp }\end{array}$ & $3^{\circ} \mathrm{C} / \mathrm{min}$ & $5^{\circ} \mathrm{C} / \mathrm{min}$ & $10^{\circ} \mathrm{C} / \mathrm{min}$ \\
\hline Yield & 1 & 1 & 1 \\
\hline $\begin{array}{c}\text { Reaction time } \\
\text { (min) }\end{array}$ & 42.25 & 31.19 & 18.23 \\
\hline
\end{tabular}

Clearly, an unitary conversion could be established even at the smallest reaction time. Regarding the actual neutralization temperature, since the evaporation of $\mathrm{H}_{2} \mathrm{O}$ is obviously endothermic, it can be assumed that the weak exothermic peak correspond to the formation of sulphate. Therefore, from Figure 3, it was possible to assume a realistic value of $170^{\circ} \mathrm{C}$ for the step III.

In reaction VI, Nickel oxide is quantitatively converted to Nickel iodide at the same temperature of the Bunsen reaction[6]; this neutralization is exothermic[6] but water and excess of Iodine (step VII) present in the HI phase are to be evaporated, leading to a global endothermic process. $\mathrm{NiI}_{2}$ is then heated up $600^{\circ} \mathrm{C}$ and quantitatively decomposed into metallic Nickel and iodine[6] (steps VIII and IX). All reactions in this part of the cycle are performed under Nitrogen.

All the gaseous products from III, V, VI, VII and IX are cooled down and reintroduced in the Bunsen reactor, where Sulfur dioxide, Sulfur trioxide and Iodine are absorbed and make available for the redox step. Iron (III) oxide from $\mathrm{V}$ is also brought back to $170^{\circ} \mathrm{C}$, that is, at the reaction III temperature.

The total balance of steps I-IX correspond to the reduction of Nickel oxide, obtaining Nickel as hydrogen source to be used on-demand (step X). Using the available thermodynamic data, this process is endoergonic and slightly endothermic[15][18][19]. The heat duty included in Table 1 considers the reaction enthalpy along with the energy necessary to heat Nickel and Water up to the reaction temperature, and the water vaporization heat. A temperature of $200^{\circ} \mathrm{C}$ is indicated by Yavor et al. for this step[17].

Assuming an unitary conversion of Nickel into Hydrogen, which might be achieved by removing the gaseous products during the reaction, and considering the ratio of the hydrogen low heating value $(240.4 \mathrm{~kJ} / \mathrm{mol})$ to the overall energy inputs, it is possible to preliminarily estimate the cycle global efficiency, equal to about 0.19 . If, on one hand, the heat duty of step $X$ can be underestimated, given the realistic necessity to operate the reaction in an excess of water, on the other hand, also advantageous heat recoveries might be conceived to increase the cycle efficiency.

\section{Conclusions}

Using both literature and experimental data, the global thermal efficiency of a sulphur-iodine modified thermochemical cycle, was assessed. The proposed cycle is based on the adoption of an intermediate metal, which can be reacted with water to quantitatively produce hydrogen on demand, with the purpose to facilitate the storage and improve the dispatchability of this solar fuel. Clearly, the use of Nickel leads to safety and environmental issues: to overcome this problem a dedicated work is now on-going to modify the proposed process employing low or no-toxic intermediates, maintaining, at the same, a high global cycle efficiency.

\section{Acknowledgments}

The activity presented in this paper have been obtained in the framework of the Project 1.2 "Heat accumulation, including electrochemical and power to gas systems, and relative interfaces with distribution networks", under the "Electric System Research" program 2019-2021, with the financial support of Italian Ministry for Ecological Transition

\section{References}

1 S. Ihara, "Feasibility of hydrogen production by direct water splitting at high temperature," Int. J. Hydrogen Energy, vol. 3, no. 3, pp. 287-296, 1978.

2 R. Pitz-Paal, "Concentrating Solar Power Systems," 2017.

3 D. W. J.H. Norman, K.J. Mysels, R. Sharp, "Studies of the sulfur-iodine thermochemical water-splitting cycle," Int. J. Hydrogen Energy, vol. 7, no. 7, pp. 545-556, 1982.

4 L. T. Salvatore Sau, Anna Chiara Tizzoni, Alberto Giaconia, Michela Lanchi, "Splitting water with renewable heat: green hydrogen beyond electrolysis," Energia, ambiente $e$ innovazione $1 / 2021$, 2021. https://www.eai.enea.it/component/jdownloads/?t ask $=$ download.send\&id $=1220 \&$ catid $=61 \&$ Itemid $=101$ (accessed Aug. 30, 2021).

5 P. Liberatore, R., Lanchi, M., Caputo, G., Felici, C., Giaconia, A., Sau, S., Tarquini, "Hydrogen production by flue gas through sulfur-iodine thermochemical process: Economic and energy evaluation," Int. J. Hydrogen Energy, vol. 37, no. 11, pp. 8939-8953, 2012.

6 S. S. Pier Paolo Prosini, Cinzia Cento, Alberto Giaconia, Giampaolo Caputo, "A modified sulphur-iodine cycle for efficient solar hydrogen production," Int. J. Hydrogen Energy, vol. 34, no. 3, pp. 1218-1225, 2009.

7 M. Lanchi et al., "Use of metallic Ni for $\mathrm{H} 2$ production in S-I thermochemical cycle: Experimental and theoretical analysis," Int. J. Hydrogen Energy, vol. 34, no. 3, pp. 1200-1207, 
2009, doi: 10.1016/j.ijhydene.2008.10.044.

G. Caputo, C. Felici, A. Giaconia, M. Lanchi, R. Liberatore, and S. Sau, "Experimental study of the bunsen reaction for the S-I thermochemical cycle," in AIChE Annual Meeting Conference Proceedings, 2005, vol. 2005.

9 A. Giaconia et al., "Experimental study of two phase separation in the Bunsen section of the sulfur-iodine thermochemical cycle," Int. J. Hydrogen Energy, vol. 32, no. 5, pp. 531-536, 2007, doi: 10.1016/j.ijhydene.2006.08.015.

10 A. Giaconia, S. Sau, G. Caputo, C. Felici, and P. Tarquini, "Continuous flow operation of a bunsen reactor in the sulfur-iodine thermochemical water-splitting cycle," 2007.

11 "Sulfuric Acid-Water Chemical Energy Storage System," Redmond, Washington, 1976.

12 P. T. A.C. Tizzoni, N. Corsaro, C. D’Ottavi, S. Licoccia, S. Sau, "Oxygen production by intermediate metal sulphates in sulphur based thermochemical water splitting cycles," Int. J. Hydrogen Energy, vol. 40, no. 11, pp. 40654083, 2015.

13 "The engineering toolbox, Water - Heat of Vaporization."

https://www.engineeringtoolbox.com/waterproperties-d_1573.html (accessed Nov. 24, 2021).

14 J. Majzlan, A. Navrotsky, R. Stevens, M. Donaldson, B. F. Woodfield, and J. BoerioGoates, "Thermodynamics of monoclinic Fe2(SO4)3," J. Chem. Thermodyn., vol. 37, no. 8, pp. 802-809, 2005, doi: 10.1016/j.jct.2004.11.021.

D. R. Lide, CRC handbook of chemistry and physics. Vol. 85. 2004.

16 R. L. and W. P. Heinz Gamsjäger (Chairman), Jerzy Bugajski, Tamas Gajda, Chemical Thermodynamics Of Nickel-Chemical Thermodynamics Volume 6. .

17 D. L. F. Yinon Yavor, Sam Goroshin, Jeffrey M. Bergthorson, "Comparative reactivity of industrial metal powders with water for hydrogen production," Int. J. Hydrogen Energy, vol. 40, no. 2, pp. 1026-1036.

18 K. H. Stern, High temperature properties and thermal decomposition of inorganic salts with oxyanions. 2000.

19 B. J. Boyle, E. G. King, and K. C. Conway, "Heats of Formation of Nickel and Cobalt Oxides (NiO and $\mathrm{CoO}$ ) of Combustion Calorimetry," $J$. Am. Chem. Soc., vol. 76, no. 14, pp. 3835-3837, 1954, doi: $10.1021 / \mathrm{ja} 01643 \mathrm{a} 072$. 